\title{
Two new species of the Clubiona corticalis-group from Yunnan Province, China (Araneae, Clubionidae)
}

\author{
Pan-Long Wu', Guo Zheng², Feng Zhang' \\ I The Key Laboratory of Invertebrate Systematics and Application, College of Life Sciences, Hebei University, \\ Baoding, Hebei 071002, P. R. China 2 College of Life Science and Chemistry, Shenyang Normal University, \\ Shenyang, Liaoning 110034, P. R. China
}

Corresponding author: Feng Zhang (dudu06042001@163.com)

Academic editor: Y. Marusik | Received 9 January 2015 | Accepted 19 March 2015 | Published 16 April 2015

http://zoobank.org/F1480639-1CC1-4399-AFFB-99B6B626CFE4

Citation: Wu P-L, Zheng G, Zhang F (2015) Two new species of the Clubiona corticalis-group from Yunnan Province, China (Araneae, Clubionidae). ZooKeys 496: 15-25. doi: 10.3897/zookeys.496.9223

\section{Abstract}

The present paper describes two new Clubiona corticalis-group species collected from Xishuangbanna, Yunnan Province of China: Clubiona submoralis sp. n. $\left(+\sigma^{\lambda}\right)$ and C. pollicaris sp. n. $\left(+\sigma^{\lambda}\right)$.

\section{Keywords}

Sac spiders, Paraclubiona, Atalia, taxonomy, South-East Asia

\section{Introduction}

Clubiona Latreille, 1804, the largest genus of the Clubionidae, currently includes 468 species (Platnick 2014) widely distributed around the world (except South America). Because of its high species diversity, several revisions have been published by Simon (1932) for the French species, Lohmander (1944) for Swedish species, Wiehle (1965) for German species, Wunderlich (2011) for European species, Edwards (1958) for the North American species, Dondale and Redner (1982) for Canadian and Alaskan species, Mikhailov (1990, 1991, 1995, 2002, 2012) for Palaearctic species, and Deeleman-Reinhold (2001) for southeast Asian species. 
Table I. A list of Clubiona corticalis-group species in China.

\begin{tabular}{|c|c|c|c|}
\hline & Species name & Known sex & Distribution \\
\hline 1 & C. altissimoides Liu et al., 2007 & 19o & Yunnan \\
\hline 2 & C. applanata Liu et al., 2007 & $\widehat{0}+9$ & Yunnan \\
\hline 3 & C. brachyptera Zhu, Ren \& Chen, 2012 & ơ & Hainan \\
\hline 4 & C. cordata Zhang \& Zhu, 2009 & $\hat{0}+0$ & Sichuan, Xizang \\
\hline 5 & C. cylindrata Liu et al., 2007 & $\widehat{0}+0$ & Yunnan \\
\hline 6 & C. didentata Zhang \& Yin, 1998 & $\hat{\sigma}$ & Yunnan \\
\hline 7 & C. kurosawai Ono, 1986 & ofo & Taiwan \\
\hline 8 & C. lamina Zhang, Zhu \& Song, 2007 & $0^{\pi}$ & Yunnan \\
\hline 9 & C. lyriformis Song \& Zhu, 1991 & 우 & Hubei \\
\hline 10 & C. moralis Song \& Zhu, 1991 & jo & Hubei \\
\hline 11 & C. parallela $\mathrm{Hu} \& \mathrm{Li}, 1987$ & ito & Xizang \\
\hline 12 & C. pyrifera Schenkel, 1936 & jot & Gansu \\
\hline 13 & C. qiyunensis Xu, Yang \& Song, 2003 & jo & Fujian, Anhui \\
\hline 14 & C. taiwanica Ono, 1994 & o우 & Yunnan, Taiwan \\
\hline 15 & C. tengchong Zhang, Zhu \& Song, 2007 & $\sigma^{\pi}$ & Yunnan \\
\hline 16 & C. yaginumai Hayashi, 1989 & ofo & Taiwan \\
\hline 17 & C. submoralis sp. n. & jo & Yunnan \\
\hline 18 & C. pollicaris sp. $\mathrm{n}$. & ioto & Yunnan \\
\hline
\end{tabular}

Clubiona corticalis-group was first recognized by Simon (1932). Atalia Thorell, 1887 (type species $A$. concinna Thorell, 1887, belongs to the corticalis-group) and subgenus Paraclubiona Lohmander, 1944 (with type species C. corticalis) are currently considered as junior synonyms of Clubiona. Species of this group can be recognized by the following characters: inflated tegulum; long filiform, spiniform, or short embolus; simple and weakly developed retrolateral tibial apophysis; the anterior position of copulatory openings (Mikhailov 1995).

Currently, the corticalis-group includes 48 species mainly distributed in Eurasia and Australia (Mikhailov 1995, Deeleman-Reinhold 2001, Liu et al. 2007). Among these, at least 18 species have been recorded from China (see Table 1).

While examining Clubiona specimens collected from Xishuangbanna Prefecture, Yunnan Province of China, we found two new species belonging to the corticalisgroup, which are described in this paper.

\section{Material and methods}

All specimens studied are stored in 75\% ethanol and deposited in the Institute of Zoology, Chinese Academy of Sciences in Beijing (IZCAS). All specimens were examined under a Tech XTL-II stereomicroscope. The photos, drawings and measurements were prepared using a Leica M205A stereomicroscope equipped with a DFC450 CCD camera and a drawing tube. Carapace length was measured from the anterior mar- 
gin to the posterior margin of the carapace medially. The eyes were measured as the maximum diameter of the lens in dorsal or frontal view. The measurements of legs are shown as total length (femur, patella, tibia, metatarsus, tarsus). The epigyne was cleared in a solution of potassium hydroxide $(\mathrm{KOH})$ and transferred to $75 \%$ ethanol for taking photos, drawing and measuring. All measurements are in millimeters.

The following abbreviations are used: ALE, anterior lateral eyes; AME, anterior median eyes; $\mathrm{B}$, bursae; $\mathrm{C}$, conductor; $\mathrm{CO}$, copulatory openings; $\mathrm{E}$, embolus; FD, fertilization ducts; MOA, median ocular area; PLE, posterior lateral eyes; PME, posterior median eyes; PPA, prolateral patellar apophysis; RFA, retrolateral femoral apophysis; RPA, retrolateral patellar apophysis; RTA, retrolateral tibial apophysis; $S$, spermathecae.

\section{Taxonomy}

Clubiona submoralis sp. $\mathrm{n}$.

http://zoobank.org/3299A436-1170-4959-9BE3-95190B84F461

Figs 1-12

Type material. Holotype $\hat{\sigma}$, CHINA, Yunnan Province, Xishuangbanna Prefecture, Mengla County, Menglun Town, XTBG (Xishuangbanna Tropical Botanical Garden), Yunnan Rubber Plantation (575 m; 21 54.46 'N, 101²15.98'E), 21 July 2007, Guo Zheng leg. Paratypes: $9 \hat{O}, 10$ ㅇ, same data as holotype.

Diagnosis. Among the Chinese species of the corticalis-group, this new species resembles $C$. moralis, but differs by: a wider and triangular embolus (filiform and coiled in $C$. moralis), presence of only one round, black marking on tegulum (several fanshaped markings in $C$. moralis); fertilization ducts opening in the medio-ventral side of the spermathecae (anteriorly in C. moralis); and the spermathecae almost as large as the bursae (the bursae twice longer than the spermathecae in $C$. moralis) (Figs 3-12).

Etymology. The species name refers to a close resemblance between the new species and C. moralis.

Description. Male. Total length 4.36-4.86. Holotype (Fig. 1): body 4.73 long; carapace 2.14 long, 1.96 wide; abdomen 2.49 long, 1.30 wide. Carapace brown. Median furrow longitudinal. In dorsal view, anterior eye row recurved, posterior eye row recurved. Eye sizes and interdistances: AME 0.10, ALE 0.11, PME 0.11, PLE 0.10; AME-AME 0.07, AME-ALE 0.06, PME-PME 0.27, PME-PLE 0.15. MOA 0.31 long, front 0.30 wide, back 0.48 wide. Chelicerae dark brown, promargin with six teeth, retromargin with three teeth. Endites brown, longer than wide. Labium dark brown, longer than wide. Sternum 1.19 long, 0.80 wide. Abdomen oval, brown, with conspicuous anterior tufts of hairs, dorsum with fine brown hairs. Legs yellow, both tibia I and II with two pairs of ventral spines, both metatarsi I and II with one pair of ventral spines. Measurements of legs: I 5.50 (1.55, 0.75, 1.57, 1.07, 0.56), II 6.02 $(1.65,0.80,1.80,1.21,0.56)$, III $4.73(1.26,0.61,1.13,1.30,0.43)$, IV 6.73 (1.78, $0.71,1.65,2.01,0.58)$. 

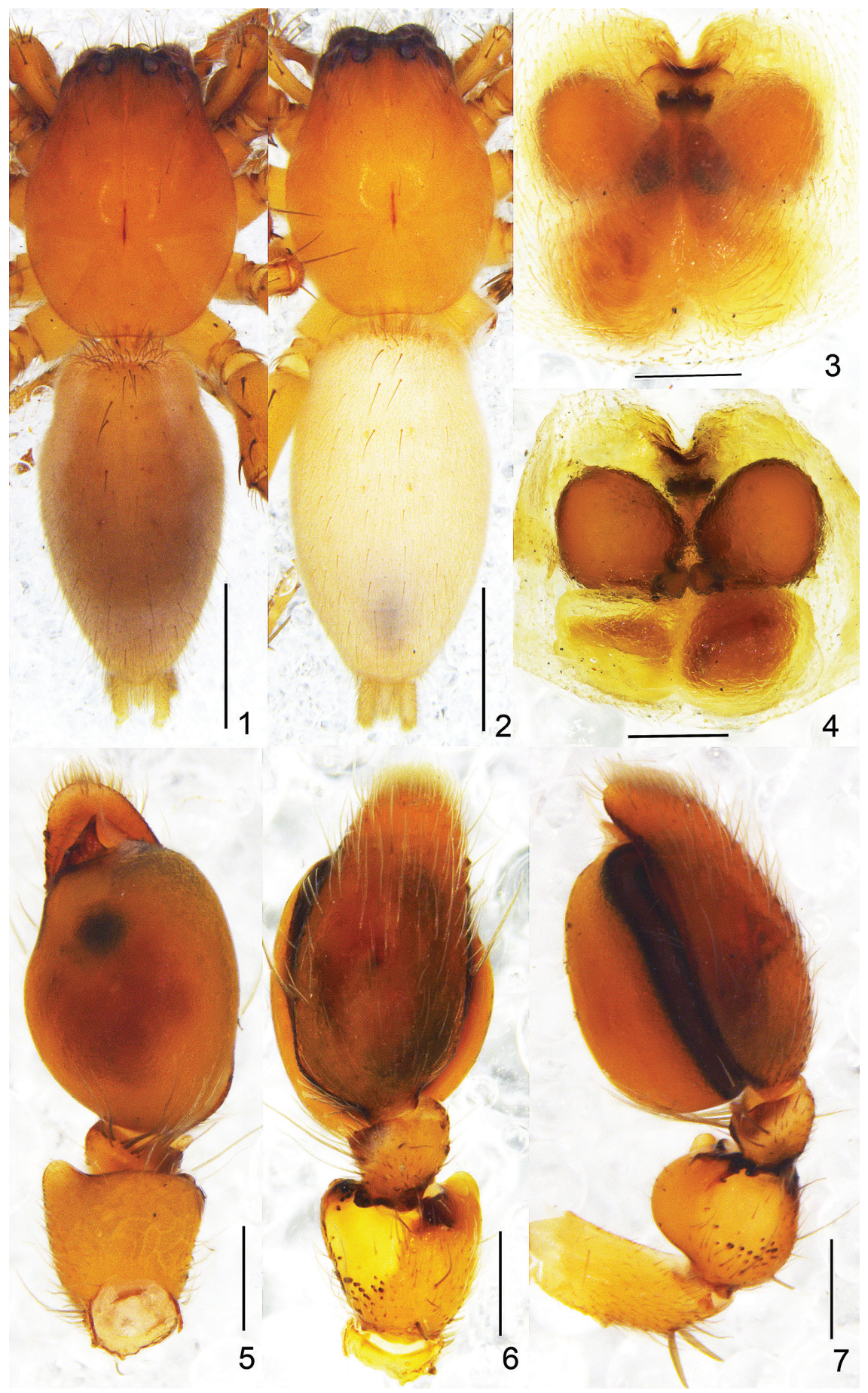

Figures I-7. Clubiona submoralis sp. n. I male habitus, dorsal view $\mathbf{2}$ female habitus, dorsal view $\mathbf{3}$ epigyne, ventral view $\mathbf{4}$ vulva $\mathbf{5}$ left male palp, ventral view $\mathbf{6}$ same, dorsal view, showing tibial apophysis 7 same, retrolateral view. Scale bars: $1 \mathrm{~mm}(\mathbf{I - 2}) ; 0.2 \mathrm{~mm}(\mathbf{3 - 7})$. 

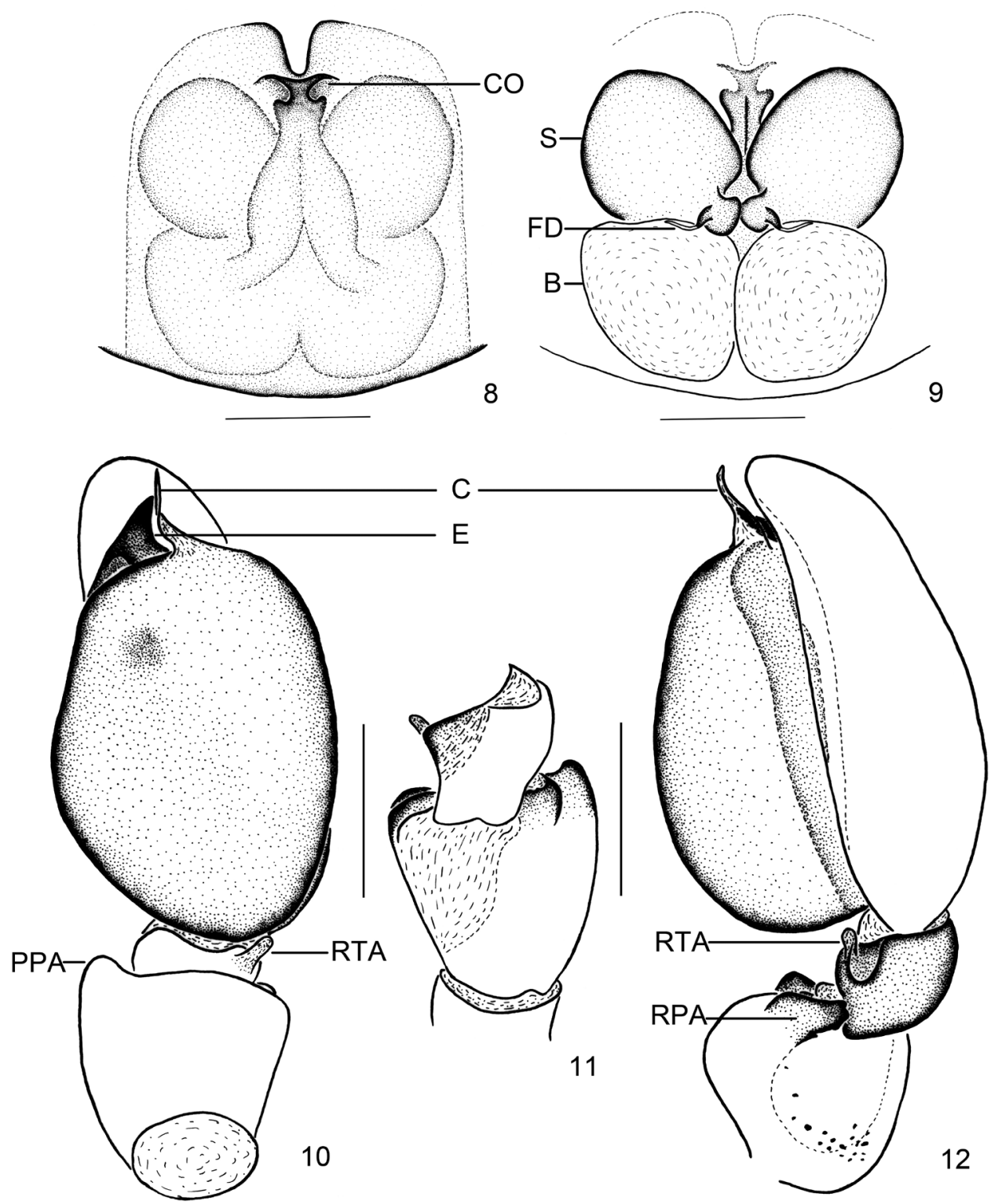

Figures 8-12. Clubiona submoralis sp. n. 8 epigyne, ventral view 9 vulva 10 left male palp, ventral view I I tibial apophysis, dorsal view $\mathbf{2}$ left male palp, retrolateral view. Scale bars: $0.25 \mathrm{~mm}$ (8- $\mathbf{8}$ ).

Palp (Figs 5-7, 10-12). Femur unmodified; patella swollen, almost globular, twice wider than tibia, and 1.5 wider than femur, with short and rounded pro- and retrolateral apophyses, retrolateral side with short modified spines near the base; tibia with small retro-ventral membranous apophysis. Cymbium longer than tegulum. Tegulum inflated, with a round, black marking medially; embolus short, wide, almost triangular 
in ventral view; conductor membranous, folded in the middle position, and almost threefold longer than wide.

Female. Total length 4.45-4.92. One paratype (Fig. 2) measured, body 4.47 long; carapace 1.87 long, 1.43 wide; abdomen 2.49 long, 1.39 wide. Eye sizes and interdistances: AME 0.10, ALE 0.11, PME 0.09, PLE 0.07; AME-AME 0.08, AME-ALE 0.04, PME-PME 0.24, PME-PLE 0.14. MOA 0.22 long, front 0.23 wide, back 0.41 wide. Sternum 0.96 long, 0.70 wide. Measurements of legs: I 4.53 (1.31, 0.66, 1.21, $0.84,0.51)$, II $5.14(1.48,0.74,1.41,0.97,0.54)$, III $4.22(1.25,0.57,0.90,1.13$, 0.37), IV $6.14(1.66,0.70,1.40,1.89,0.49)$. Coloration lighter than in male. Other characters as in male.

Epigyne (Figs 3-4, 8-9). Copulatory openings located anteriorly; in ventral view, the anterior part of copulatory ducts well visible and extending posteriorly, then connecting to bursae; spermathecae located anterior to bursae, both of them almost spherical, and with the same size as bursae.

Distribution. China (Yunnan).

\section{Clubiona pollicaris sp. $\mathbf{n}$.}

http://zoobank.org/A815DA83-1925-4B07-BB84-D2DC0D5DA3C8

Figs 13-19, 23-27

Type material. Holotype $\widehat{\delta}$, CHINA, Yunnan Province, Xishuangbanna Prefecture, Mengla County, Menglun Nature Reserve (710 m; 21 $\left.{ }^{\circ} 57.70^{\prime} \mathrm{N}, 101^{\circ} 11.89^{\prime} \mathrm{E}\right), 7 \mathrm{Au}-$ gust 2007, Guo Zheng leg. Paratypes: 6 Oे, 6 क , same data as holotype.

Diagnosis. The new species differs from all other Clubiona species by a very long retrolateral femoral apophysis (almost as long as femur) and resembles C. qiyunensis (Figs 20-22; also see Wu and Zhang (2014): 211, f. 13-23), but differs by: a smaller and inconspicuous embolus; the much longer femoral apophysis (in C. qiyunensis, femoral apophysis is short, less than diameter of femur); a thumb-shaped prolateral patellar apophysis; anteriorly situated spermathecae; and rectangular bursae (Figs 15-19, 23-27).

Etymology. The species name is derived from the Latin word "pollicaris", and refers to the prolateral patellar apophysis, which in ventral view is thumb-shaped.

Description. Male. Total length 3.20-3.49. Holotype (Fig. 13) body 3.27 long; carapace 1.51 long, 1.45 wide; abdomen 1.61 long, 0.90 wide. Carapace brown. Median furrow longitudinal. Both anterior and posterior eye row recurved in dorsal view. Eye sizes and interdistances: AME 0.06, ALE 0.10, PME 0.09, PLE 0.08; AME-AME 0.06, AME-ALE 0.03, PME-PME 0.19, PME-PLE 0.08. MOA 0.21 long, front 0.19 wide, back 0.37 wide. Chelicerae brown, promargin with five teeth, retromargin with four teeth. Both endites and labium brown, longer than wide. Sternum 0.83 long, 0.56 wide. Abdomen oval, brown, with conspicuous anterior tufts of hairs, dorsum with fine yellow hairs. Legs brown, both tibia I and II with two pairs of ventral spines, both metatarsi I and II with one pair of ventral spines. Measurements of legs: I 3.09 (0.84, 0.47, 0.83, 0.62, 0.33), II 3.46 (0.90, 


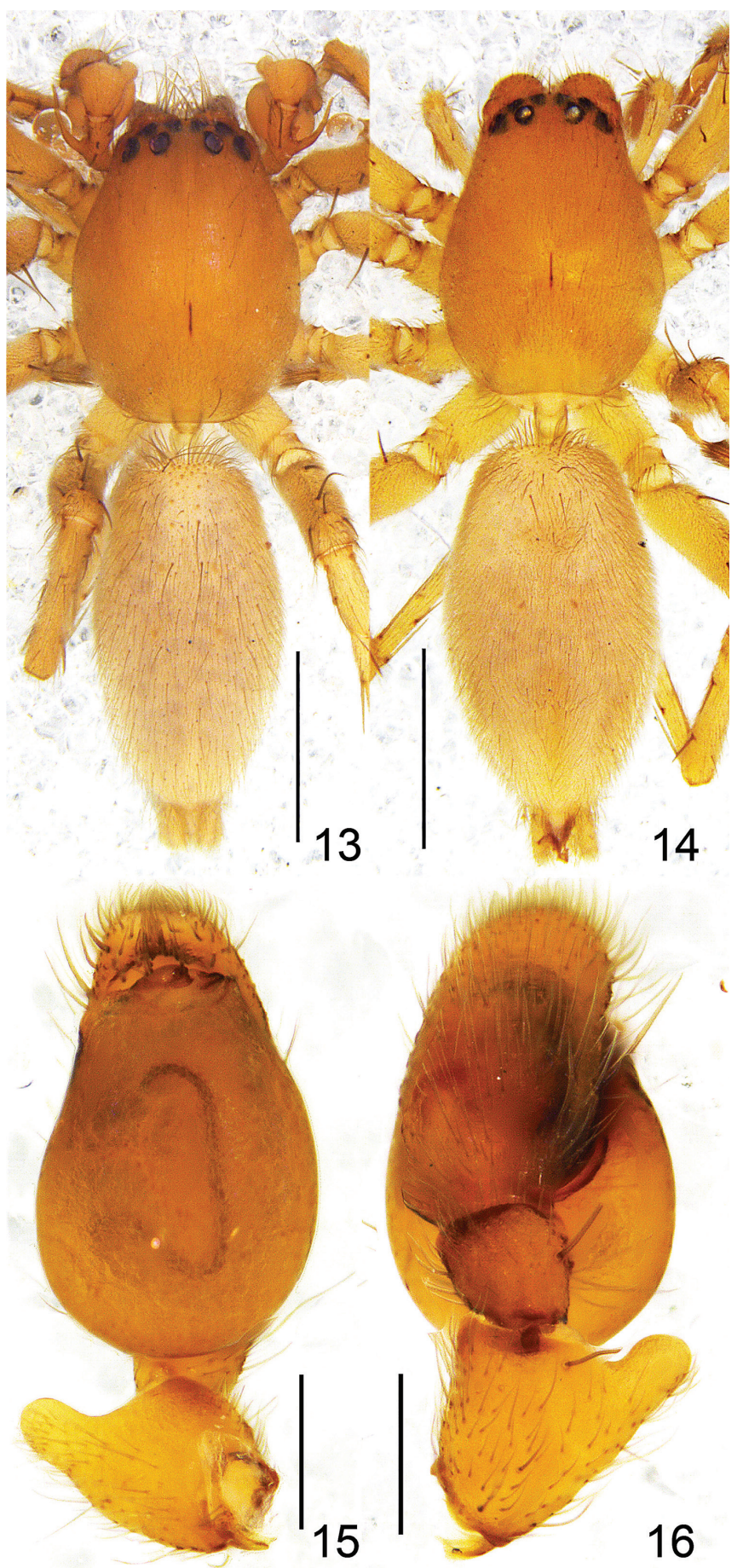

Figures 13-16. Clubiona pollicaris sp. n. I3 male habitus, dorsal view I4 female habitus, dorsal view 15 left male palp, ventral view 16 same, dorsal view, showing patellar apophysis. Scale bars: $1 \mathrm{~mm}$ (I3-I4); $0.2 \mathrm{~mm}(\mathbf{I 5}, \mathbf{I 6})$. 


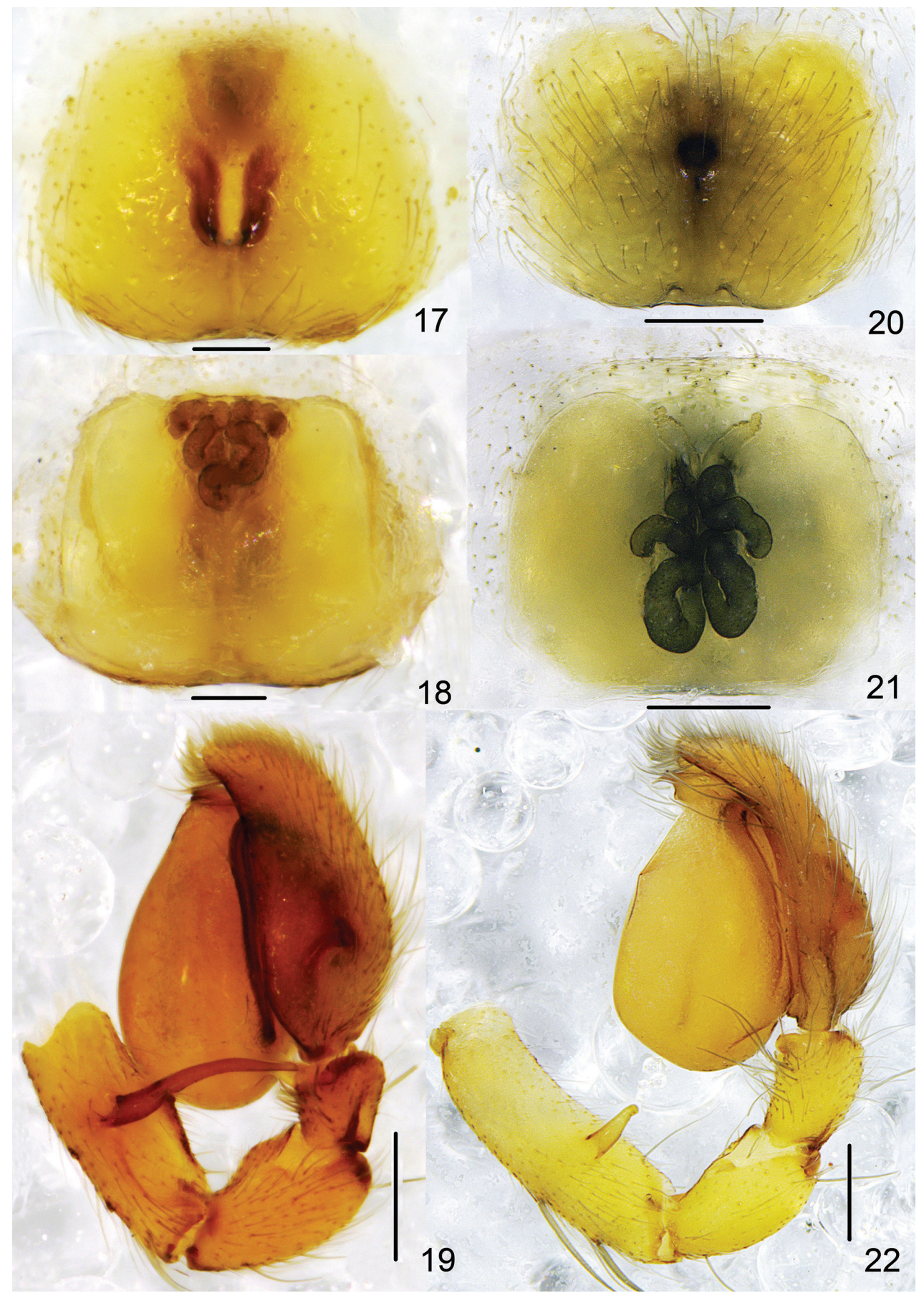

Figures 17-22. 17-19 Clubiona pollicaris sp. n. 17 epigyne, ventral view $\mathbf{8}$ vulva $\mathbf{1 9}$ left male palp, retrolateral view; 20-22 Clubiona qiyunensis Xu, Yang \& Song, 2003. 20 epigyne, ventral view $2 \mathbf{I}$ vulva 22 left male palp, retrolateral view. Scale bars: $0.1 \mathrm{~mm}(\mathbf{I 7}, \mathbf{I} \mathbf{8}) 0.2 \mathrm{~mm}(\mathbf{I}$-22). 

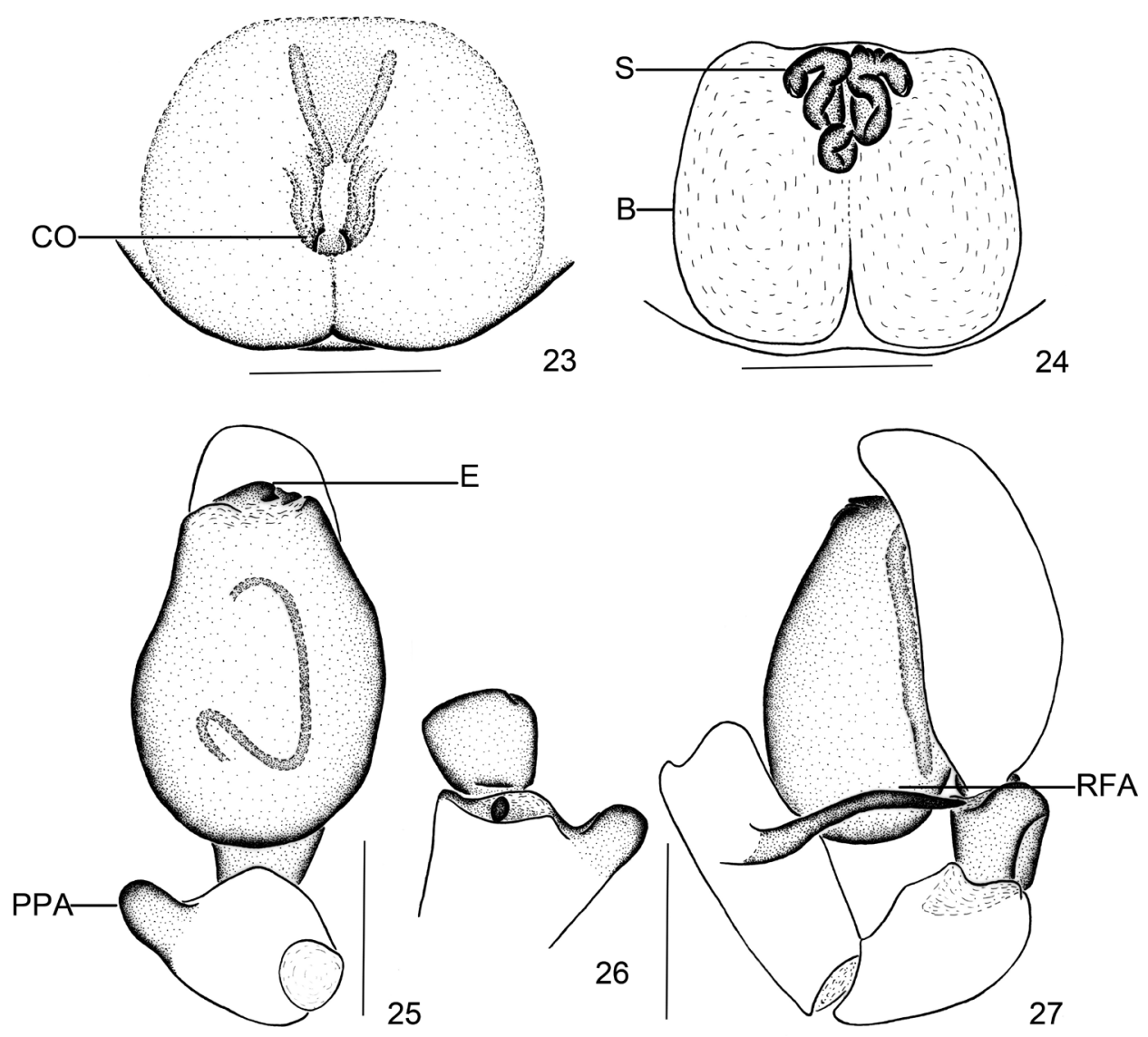

Figures 23-27. Clubiona pollicaris sp. n. 23 epigyne, ventral view $\mathbf{2 4}$ vulva $\mathbf{2 5}$ left male palp, ventral view 26 patellar apophysis, dorsal view 27 left male palp, retrolateral view. Scale bars: 0.25 mm (23-27).

$0.50,1.02,0.69,0.35)$, III $2.92(0.84,0.43,0.63,0.76,0.26)$, IV $4.11(1.18,0.50$, $0.96,1.15,0.32)$.

Palp (Figs 15-16, 19, 25-27). Femur modified, with long and thin retrolateral apophysis originating from median part, apophysis longer than tibia and subequal in length to femur; patella twice longer and 1.5 wider than tibia, with a round apophysis and thumb-shaped prolateral apophysis; tibia without apophyses; cymbium shorter than tegulum; tegulum inflated; sperm duct obvious, almost straight in retrolateral view; embolus short, originating from the apical tegulum prolaterally, directed almost horizontally.

Female. Total length 3.12-3.92. One paratype (Fig. 14) measured: body 3.90 long, carapace 1.52 long, 1.13 wide; abdomen 2.09 long, 1.18 wide. Eye sizes and interdistances: AME 0.07, ALE 0.09, PME 0.08, PLE 0.07; AME-AME 0.08, AMEALE 0.05, PME-PME 0.20, PME-PLE 0.12. MOA 0.21 long, front 0.20 wide, back 
0.35 wide. Sternum 0.85 long, 0.57 wide. Measurements of legs: I 2.69 (0.84, 0.38, $0.64,0.51,0.32)$, II $3.09(0.90,0.46,0.79,0.60,0.34)$, III $2.63(0.80,0.35,0.55$, $0.67,0.26)$, IV $3.92(1.02,0.50,0.93,1.10,0.37)$. Coloration slightly lighter than in male; other characters as in male.

Epigyne (Figs 17-18, 23-24). Copulatory openings small, located almost in the centre of the epigynal plate; in ventral view copulatory ducts inconspicuous; spermathecae long, tubular and sinuous; bursae large, membranous, almost rectangular.

Distribution. China (Yunnan).

Comments. Retrolateral femoral apophysis is known only in three species of Clubionidae: Clubiona pollicaris, C. qiyunensis and C. brachyptera.

\section{Acknowledgements}

We thank Dr. Shuqiang Li (Institute of Zoology, Chinese Academy of Sciences, Beijing) for providing valuable specimens. We are grateful to Dr. K.G. Mikhailov and Dr. R. Bosmans for reviewing the manuscript. Prof. Victor Fet kindly helped reviewing the English of the manuscript. This work was supported by the National Natural Science Foundation of China (No. 31372154, 31172121, 31372224).

\section{References}

Deeleman-Reinhold CL (2001) Forest spiders of South East Asia: with a revision of the sac and ground spiders (Araneae: Clubionidae, Corinnidae, Liocranidae, Gnaphosidae, Prodidomidae and Trochanteriidae). Brill, Leiden, 591 pp.

Dondale CD, Redner JH (1982) The insects and arachnids of Canada, Part 9. The sac spiders of Canada and Alaska, Araneae: Clubionidae and Anyphaenidae. Research Branch Agriculture Canada Publication 1724: 1-194.

Edwards RJ (1958) The spider subfamily Clubioninae of the United States, Canada and Alaska (Araneae: Clubionidae). Bulletin of the Museum of Comparative Zoology, Harvard 118(6): 365-436.

Hayashi T (1989) Four new species of the genus Clubiona (Araneae: Clubionidae) from Japan. In: Nishikawa Y, Ono H (Eds) Arachnological Papers Presented to Takeo Yaginuma on the Occasion of his Retirement. Osaka Arachnologists' Group, Osaka, 103-110.

$\mathrm{Hu}$ JL, Li AH (1987) The spiders collected from the fields and the forests of Xizang Autonomous Region, China. (II). Agricultural Insects, Spiders, Plant Diseases and Weeds of Xizang 2: $247-353$.

Huang WJ, Chen SH (2012) The Spider Fauna of Taiwan. Araneae. Miturgidae, Anyphaenidae, Clubionidae. National Taiwan Normal University, Taipei, 130 pp.

Liu P, Yan HM, Griswold C, Ubick D (2007) Three new species of the genus Clubiona from China (Araneae: Clubionidae). Zootaxa 1456: 63-68.

Lohmander H (1944) Vorläufige Spinnennotizen. Arkiv för Zoologi 35(A, 16): 1-21. 
Mikhailov KG (1990) The spider genus Clubiona Latreille 1804 in the Soviet Far East, 1 (Arachnida, Aranei, Clubionidae). Korean Arachnology 5(2): 139-175.

Mikhailov KG (1991) The spider genus Clubiona Latreille 1804 in the Soviet Far East, 2 (Arachnida, Aranei, Clubionidae). Korean Arachnology 6(2): 207-235.

Mikhailov KG (1995) Erection of infrageneric groupings within the spider genus Clubiona Latreille, 1804 (Aranei Clubionidae): a typological approach. Arthropoda Selecta 4(2): 33-48.

Mikhailov KG (2002) The spider genus Clubiona Latreille, 1804 (Aranei: Clubionidae) in the fauna of the former USSR: 2003 update. Arthropoda Selecta 11: 283-317.

Mikhailov KG (2012) Reassessment of the spider genus Clubiona (Aranei, Clubionidae). Vestnik Zoologii 46(2): 177-180. doi: 10.2478/v10058-012-0015-z

Ono H (1994) Spiders of the genus Clubiona from Taiwan (Araneae: Clubionidae). Acta Arachnologica, Tokyo 43: 71-85. doi: 10.2476/asjaa.43.71

Ono H (1986) A new spider of the group of Clubiona corticalis (Araneae, Clubionidae) found in Japan. In: Entomological Papers Presented to Yoshihiko Kurosawa on the Occasion of his Retirement. Tokyo, 19-25.

Platnick NI (2014) The World Spider Catalog, Version 15.5. American Museum of Natural History. http://www.wsc.nmbe.ch/family/17/Clubionidae [accessed 30 December 2014]

Schenkel E (1936) Schwedisch-chinesische wissenschaftliche Expedition nach den nordwestlichen Provinzen Chinas, unter Leitung von Dr Sven Hedin und Prof. Sü Ping-chang. Araneae gesammelt vom schwedischen Artz der Exped. Arkiv för Zoologi 29(A1): 1-314.

Simon E (1932) Les arachnides de France. Tome VI. Synopsis générale et catalogue des espèces françaises de l'ordre des Araneae; 4e partie. Paris, 6: 773-978.

Song DX, Zhu MS, Gao SS, Guan JD (1991) Six species of clubionid spiders (Araneae: Clubionidae) from China. Journal of Xinjiang University 8: 66-72.

Wiehle H (1965) Die Clubiona-Arten Deutschlands, ihre natürliche Gruppierung und die Einheitlichkeit im Bau ihrer Vulva (Arach., Araneae). Senckenbergiana Biologica 46: 471-505.

Wu PL, Zhang F (2014) A new species of the spider genus Clubiona from China, with description of the male of Clubiona qiyunensis (Araneae: Clubionidae). Acta Zoologica Academiae Scientiarum Hungaricae 60(3): 207-215.

Wunderlich J (2011) Extant and fossil spiders (Araneae). Beträge zur Araneologie 6: 1-640.

Xu YJ, Yang JY, Song DX (2003) Two new species of the genus Clubiona from Anhui, China (Araneae: Clubionidae). Journal of Hebei University (Natural Science Edition) 23: 411-413.

Zhang F, Zhu MS (2009) Three new species of the genus Clubiona from Xizang and Sichuan, China (Araneae, Clubionidae). Acta Zootaxonomica Sinica 34: 725-729.

Zhang F, Zhu MS, Song DX (2007) Three new species of the genus Clubiona from Yunnan Province, China (Araneae, Clubionidae). Journal of Hebei University, Natural Science Edition 27: 407-411.

Zhang YJ, Yin CM (1998) Six new species of the spiders of genus Clubiona from China (Araneae: Clubionidae). Acta Zootaxonomica Sinica 23: 9-17.

Zhu BR, Ren HQ, Chen J (2012) A new species of the genus Clubiona Latreille (Araneae, Clubionidae) from Hainan Island, China. Zootaxa 3167: 53-56. 